\title{
A Hybrid Technique for Order Preference in Decision-Making
}

\author{
Ismat Beg' and Tabasam Rashid ${ }^{2}$ \\ ${ }^{1}$ Lahore School of Economics, Lahore 53200, Pakistan \\ ${ }^{2}$ University of Management and Technology, Lahore 53200, Pakistan \\ Correspondence should be addressed to Tabasam Rashid; tabasam.rashid@gmail.com
}

Received 23 November 2014; Revised 23 January 2015; Accepted 8 February 2015

Academic Editor: Rosana Rodriguez-Lopez

Copyright (C) 2015 I. Beg and T. Rashid. This is an open access article distributed under the Creative Commons Attribution License, which permits unrestricted use, distribution, and reproduction in any medium, provided the original work is properly cited.

\begin{abstract}
We propose a hybrid technique by merging fuzzy version of the classical technique for order preference by similarity to ideal solution and decision-making trial and evaluation laboratory technique for trapezoidal fuzzy numbers, where interaction phenomena among the decision-making problem and weights are taken into account. The feasibility of this new method is demonstrated by applying it to an example.
\end{abstract}

\section{Introduction}

Modeling of real world decision-making problems is difficult because these problems are defined under uncertain conditions. Multiple criteria decision-making (MCDM) techniques are used for evaluating the alternatives in terms of a number of quantitative and qualitative criteria with the purpose of selection or ranking the alternatives [1]. MCDM could be appropriate for evaluating a set of alternatives with respect to three objectives. The first one is selecting the best alternative among a set of alternatives. The second objective is sorting the alternatives into relatively homogeneous groups or arranging them in a preference order. The last objective is ranking the alternatives in a descending or ascending order. Great efforts in the field of developing and improving MCDM techniques resulted in numerous approaches for effectively addressing general multiple criteria analysis decision problems. Özcan et al. [1] gave a comparison and application of these techniques depending on the structure of the decision problem. Zadeh $[2,3]$ proposed the concept of fuzzy set theory and successfully used it to handle uncertainty in multiple criteria decision-making problems. The fuzzy versions of MCDM techniques are more suitable for subjective and qualitative assessments in the evaluation processes than the classical MCDM techniques applying crisp values $[4,5]$. Dubois in his paper [6] discussed new significant techniques of decision analysis. He suggested the use of membership function, linguistic variables, and fuzzy intervals. Recently, [7-9] studied fuzzy version of the classical technique for order preference by similarity to ideal solution (TOPSIS) due to [10] for multiattribute/multicriteria decision-making (MADM/MCDM) problems. Decisionmaking trial and evaluation laboratory (DEMATEL) method is a comprehensive method to analyze a structural model between complex factors. It is recently studied by several researchers [11]. This technique identifies the importance of each criterion in a network of other criteria relationships [12]. Jeng and Tzeng [13] gave the fuzzy DEMATEL method to handle the vagueness in DEMATEL. Deng [14] proposed a new similarity technique for MCDM. This technique works on the concept that the most preferred alternative should have the highest degree of similarity to the positive ideal solution and the lowest degree of similarity to the negative ideal solution. In this paper, we propose a hybrid technique by merging TOPSIS and Deng's technique [14] for trapezoidal fuzzy numbers, where interaction phenomena among the decision-making problem and weights are taken into account.

This paper is organized as follows. In Section 2, we review fuzzy set and some preliminary concepts needed in the sequel. In Section 3, we review fuzzy DEMATEL method for trapezoidal fuzzy numbers. In Section 4, we proposed a modified version of fuzzy similarity MCDM for trapezoidal fuzzy numbers in some steps. An illustrative example is given to see the feasibility of the proposed method. Conclusion is given in the last section. 


\section{Preliminaries}

Some preliminary concepts are given in this section for subsequent use.

Let $X$ be a crisp universe of generic elements; a fuzzy set $A$ in the universe $X$ is a mapping from $X$ to $[0,1]$. For any $x \in X$, the value $A(x)$ is called the degree of membership of $x$ in $A$.

Fuzzy data is a data type with imprecision or with a source of uncertainty not caused by randomness, but due to ambiguity. Examples of fuzzy data types can easily be found in natural language. It is generally more convenient and useful in describing fuzzy data to use trapezoidal fuzzy numbers [15]. Trapezoidal fuzzy numbers are the best way to model the vagueness of human knowledge in decision problems. Zimmermann [16, Subsubsection 5.3.2] defined the trapezoidal fuzzy numbers as follows.

A function " $F$ " is given by

$$
F(x)= \begin{cases}0 & \text { if } x<x_{1} \text { or } x>x_{4} \\ \frac{x-x_{1}}{x_{2}-x_{1}} & \text { if } x_{1} \leq x<x_{2} \\ 1 & \text { if } x_{2} \leq x \leq x_{3} \\ \frac{x-x_{4}}{x_{3}-x_{4}} & \text { if } x_{3}<x \leq x_{4}\end{cases}
$$

where $0 \leq x_{1}<x_{2}<x_{3}<x_{4}$ is called trapezoidal fuzzy number. Symbolically a trapezoidal fuzzy number $F$ is denoted by $\left(x_{1}, x_{2}, x_{3}, x_{4}\right)$ (see [17, page 330]).

Definition 1 (see [18]). Constant “ $k$ " multiple of trapezoidal fuzzy number $A$ is defined as follows:

$$
k A=k\left(x_{1}, x_{2}, x_{3}, x_{4}\right)=\left(k \times x_{1}, k \times x_{2}, k \times x_{3}, k \times x_{4}\right),
$$$$
\text { where } A=\left(x_{1}, x_{2}, x_{3}, x_{4}\right) \text { and } k \in[0,1] \text {. }
$$

Definition 2 (see [18]). Product of two trapezoidal fuzzy numbers $A$ and $B$ is defined as follows:

$$
\begin{aligned}
A \times B & =\left(x_{1}, x_{2}, x_{3}, x_{4}\right) \times\left(y_{1}, y_{2}, y_{3}, y_{4}\right) \\
& =\left(x_{1} \times y_{1}, x_{2} \times y_{2}, x_{3} \times y_{3}, x_{4} \times y_{4}\right),
\end{aligned}
$$

where $A=\left(x_{1}, x_{2}, x_{3}, x_{4}\right)$ and $B=\left(y_{1}, y_{2}, y_{3}, y_{4}\right)$.

Definition 3 (see [18]). Addition of two trapezoidal fuzzy numbers $A$ and $B$ is defined as follows:

$$
\begin{aligned}
A+B & =\left(x_{1}, x_{2}, x_{3}, x_{4}\right)+\left(y_{1}, y_{2}, y_{3}, y_{4}\right) \\
& =\left(x_{1}+y_{1}, x_{2}+y_{2}, x_{3}+y_{3}, x_{4}+y_{4}\right),
\end{aligned}
$$

where $A=\left(x_{1}, x_{2}, x_{3}, x_{4}\right)$ and $B=\left(y_{1}, y_{2}, y_{3}, y_{4}\right)$.

\section{Fuzzy DEMATEL Method}

DEMATEL is a comprehensive method for analysis and relationship between criterion and its influence on the other criteria [11-13]. The DEMATEL method is summarized by Jeng and Tzeng [13]. The fuzzy DEMATEL method is presented in an algorithmic form as below.
TABLE 1: Linguistic variable for the importance.

\begin{tabular}{lc}
\hline Linguistic variable & $\begin{array}{c}\text { Corresponding trapezoidal fuzzy } \\
\text { numbers }\end{array}$ \\
\hline No influence & $(0,0,0,0.25)$ \\
Very low influence & $(0,0.25,0.5,0.55)$ \\
Low influence & $(0.5,0.6,0.65,0.7)$ \\
High influence & $(0.68,0.75,0.8,0.85)$ \\
Very high influence & $(0.8,0.9,0.95,1)$ \\
\hline
\end{tabular}

Step 1. Determining the direct relation matrix in the fuzzy environment $\widetilde{X}=\left[\widetilde{x}_{i j}\right]_{n \times n}$ shows the relationship among the criteria based on the opinion of decision-makers by linguistic variable. Thus, in this matrix $\widetilde{X}, \widetilde{x}_{i j}$ represents the influential relation of criterion $i$ on criterion $j$ in terms of trapezoidal fuzzy number, which is shown as follows:

$$
\tilde{x}_{i j}=\left(a_{i j}, b_{i j}, c_{i j}, d_{i j}\right) .
$$

Step 2 (normalizing the fuzzy direct relation matrix). The normalized fuzzy direct relation matrix $\widetilde{X}^{\prime}$ is calculated from $\widetilde{X}$ as follows:

$$
\begin{gathered}
s=\frac{1}{\max _{i=1}^{n}\left(\sum_{j=1}^{n} d_{i j}\right)} \\
\widetilde{X}^{\prime}=s \times \widetilde{X} .
\end{gathered}
$$

Step 3 (attaining the fuzzy total relation matrix). Consider

$$
\widetilde{T}=\widetilde{X}^{\prime}\left\{\left(\widetilde{I}-\widetilde{X}^{\prime}\right)^{-1}\right\}
$$

in which $\widetilde{I}$ is denoted by the identity matrix.

In this step, the total relation fuzzy matrix $\widetilde{T}$ is calculated through four $T^{a}, T^{b}, T^{c}$, and $T^{d}$ matrices. For example, consider the $T^{d}$ matrix:

$$
\widetilde{T}^{d}=X^{\prime d}\left\{\left(I-X^{\prime d}\right)^{-1}\right\}
$$

Step 4 (calculating the prominence matrix). Consider

$$
\widetilde{R}=\left[\widetilde{R}_{i}\right]_{n \times 1},
$$

where $\widetilde{R}_{i}=\sum_{j=1}^{n} \widetilde{T}_{i j}$ and $i=1,2, \ldots, n$.

Consider

$$
\widetilde{C}=\left[\widetilde{C}_{j}\right]_{1 \times n},
$$

where $\widetilde{C}_{j}=\sum_{i=1}^{n} \widetilde{T}_{i j}$ and $j=1,2, \ldots, n$.

Finally $\widetilde{P}$ matrix, which is made by adding $\widetilde{R}$ and $\widetilde{C}^{t}$ (transpose of the matrix $\widetilde{C}$ ), represents the importance of each criterion in a network of relationships:

$$
\widetilde{P}=\widetilde{R}+\widetilde{C}^{t}
$$

We use $\widetilde{P}$ matrix as the weights of components in fuzzy similarity method. 
TABLE 2: The fuzzy direct relation matrix.

\begin{tabular}{lcccr}
\hline & FAC & BEH & LR & SC \\
\hline FAC & $(0.000,0.000,0.000,0.000)$ & $(0.100,0.250,0.350,0.500)$ & $(0.700,0.950,0.980,1.000)$ & $(0.550,0.800,0.900,0.950)$ \\
BEH & $(0.050,0.013,0.250,0.375)$ & $(0.000,0.000,0.000,0.000)$ & $(0.100,0.200,0.350,0.500)$ & $(0.400,0.600,0.800,0.900)$ \\
LR & $(0.100,0.200,0.400,0.500)$ & $(0.200,0.400,0.500,0.600)$ & $(0.000,0.000,0.000,0.000)$ & $(0.600,0.750,0.900,1.000)$ \\
SC & $(0.100,0.320,0.500,0.600)$ & $(0.400,0.600,0.800,0.900)$ & $(0.450,0.600,0.800,0.900)$ & $(0.000,0.000,0.000,0.000)$ \\
KM & $(0.500,0.700,0.900,1.000)$ & $(0.100,0.300,0.500,0.550)$ & $(0.100,0.250,0.500,0.600)$ & $(0.300,0.450,0.600,0.800)$ \\
PUB & $(0.056,0.150,0.350,0.400)$ & $(0.500,0.600,0.800,0.900)$ & $(0.250,0.300,0.500,0.600)$ & $(0.500,0.600,0.850,1.000)$ \\
SOA & $(0.400,0.600,0.800,0.900)$ & $(0.200,0.400,0.600,0.700)$ & $(0.070,0.200,0.450,0.550)$ & $(0.070,0.150,0.350,0.400)$ \\
\hline & KM & \multicolumn{2}{c}{ PUB } & $(0.700,0.950,0.980,1.000)$ \\
\hline FAC & $(0.650,0.900,0.940,0.975)$ & $(0.625,0.875,0.920,1.000)$ & $(0.200,0.400,0.600,0.700)$ \\
BEH & $(0.350,0.600,0.700,0.850)$ & $(0.600,0.800,0.900,1.000)$ & $(0.200,0.400,0.600,0.650)$ \\
LR & $(0.400,0.600,0.800,0.900)$ & $(0.200,0.350,0.650,0.750)$ & $(0.300,0.450,0.550,0.800)$ \\
SC & $(0.350,0.500,0.750,0.800)$ & $(0.070,0.200,0.400,0.500)$ & $(0.070,0.200,0.500,0.550)$ \\
KM & $(0.000,0.000,0.000,0.000)$ & $(0.200,0.400,0.700,0.750)$ & $(0.600,0.700,0.900,1.000)$ \\
PUB & $(0.500,0.750,0.850,0.950)$ & $(0.000,0.000,0.000,0.000)$ & $(0.000,0.000,0.000,0.000)$ \\
SOA & $(0.500,0.600,0.800,0.950)$ & $(0.500,0.800,0.900,1.000)$ &
\end{tabular}

TABLE 3: The normalized fuzzy direct relation matrix.

\begin{tabular}{lcccr}
\hline & FAC & BEH & LR & SC \\
\hline FAC & $(0.000,0.000,0.000,0.000)$ & $(0.018,0.046,0.064,0.092)$ & $(0.129,0.175,0.180,0.184)$ & $(0.101,0.147,0.166,0.175)$ \\
BEH & $(0.009,0.002,0.046,0.069)$ & $(0.000,0.000,0.000,0.000)$ & $(0.018,0.037,0.064,0.092)$ & $(0.074,0.110,0.147,0.166)$ \\
LR & $(0.018,0.037,0.074,0.092)$ & $(0.037,0.074,0.092,0.110)$ & $(0.000,0.000,0.000,0.000)$ & $(0.110,0.138,0.166,0.184)$ \\
SC & $(0.018,0.059,0.092,0.110)$ & $(0.074,0.110,0.147,0.166)$ & $(0.083,0.110,0.147,0.166)$ & $(0.000,0.000,0.000,0.000)$ \\
KM & $(0.092,0.129,0.166,0.184)$ & $(0.018,0.055,0.092,0.101)$ & $(0.018,0.046,0.092,0.110)$ & $(0.055,0.083,0.110,0.147)$ \\
PUB & $(0.010,0.028,0.064,0.074)$ & $(0.092,0.110,0.147,0.166)$ & $(0.046,0.055,0.092,0.110)$ & $(0.092,0.110,0.156,0.184)$ \\
SOA & $(0.074,0.110,0.147,0.166)$ & $(0.037,0.074,0.110,0.129)$ & $(0.013,0.037,0.083,0.101)$ & $(0.013,0.028,0.064,0.074)$ \\
\hline & KM & \multicolumn{2}{c}{ PUB } & SOA \\
\hline FAC & $(0.120,0.166,0.173,0.179)$ & $(0.115,0.161,0.169,0.184)$ & $(0.129,0.175,0.180,0.184)$ \\
BEH & $(0.064,0.110,0.129,0.156)$ & $(0.110,0.147,0.166,0.184)$ & $(0.037,0.074,0.110,0.129)$ \\
LR & $(0.074,0.110,0.147,0.166)$ & $(0.037,0.064,0.120,0.138)$ & $(0.037,0.074,0.110,0.120)$ \\
SC & $(0.064,0.092,0.138,0.147)$ & $(0.013,0.037,0.074,0.092)$ & $(0.055,0.083,0.101,0.147)$ \\
KM & $(0.000,0.000,0.000,0.000)$ & $(0.037,0.074,0.129,0.138)$ & $(0.013,0.037,0.092,0.101)$ \\
PUB & $(0.092,0.138,0.156,0.175)$ & $(0.000,0.000,0.000,0.000)$ & $(0.110,0.129,0.166,0.184)$ \\
SOA & $(0.092,0.110,0.147,0.175)$ & $(0.092,0.147,0.166,0.184)$ & $(0.000,0.000,0.000,0.000)$ \\
\hline
\end{tabular}

TABLE 4: The fuzzy total relation matrix.

\begin{tabular}{lcccc}
\hline & FAC & BEH & LR & SC \\
\hline FAC & $(0.0369,0.1132,0.3193,0.6678)$ & $(0.0598,0.1782,0.4063,0.805)$ & $(0.1602,0.2769,0.4946,0.8651)$ & $(0.1532,0.2914,0.5476,0.9906)$ \\
BEH & $(0.0265,0.0659,0.2749,0.6072)$ & $(0.0252,0.0774,0.2539,0.5882)$ & $(0.0387,0.099,0.3036,0.6579)$ & $(0.1007,0.1872,0.4212,0.8267)$ \\
LR & $(0.0358,0.1007,0.315,0.6356)$ & $(0.0578,0.1473,0.3524,0.6948)$ & $(0.022,0.0706,0.2615,0.5846)$ & $(0.1322,0.2171,0.4567,0.8521)$ \\
SC & $(0.0356,0.118,0.3243,0.659)$ & $(0.0887,0.176,0.39,0.7467)$ & $(0.0963,0.17,0.3855,0.7368)$ & $(0.0306,0.0957,0.3104,0.7076)$ \\
KM & $(0.101,0.1755,0.3865,0.6994)$ & $(0.0349,0.1231,0.3465,0.6771)$ & $(0.0422,0.1182,0.3474,0.6793)$ & $(0.0802,0.1686,0.4124,0.8158)$ \\
PUB & $(0.0371,0.1029,0.3282,0.6691)$ & $(0.1153,0.1874,0.4194,0.7894)$ & $(0.0691,0.1272,0.3643,0.7301)$ & $(0.1245,0.2016,0.4721,0.9072)$ \\
SOA & $(0.0913,0.1688,0.3824,0.7136)$ & $(0.0581,0.1508,0.3724,0.7277)$ & $(0.0381,0.1139,0.347,0.6963)$ & $(0.049,0.1328,0.3876,0.7932)$ \\
\hline & KM & PUB & SOA \\
\hline FAC & $(0.1799,0.337,0.595,1.0515)$ & $(0.156,0.3036,0.5565,0.985)$ & $(0.1698,0.3043,0.539,0.9476)$ \\
BEH & $(0.0957,0.2043,0.4362,0.8648)$ & $(0.128,0.2194,0.441,0.8294)$ & $(0.0636,0.15,0.3767,0.757)$ \\
LR & $(0.103,0.2085,0.4724,0.8839)$ & $(0.0593,0.1524,0.4233,0.8035)$ & $(0.0597,0.1531,0.3941,0.7591)$ \\
SC & $(0.0936,0.1948,0.4603,0.8835)$ & $(0.0411,0.1345,0.3856,0.7848)$ & $(0.0738,0.1617,0.3824,0.7907)$ \\
KM & $(0.0318,0.107,0.3432,0.7324)$ & $(0.0599,0.1603,0.4319,0.7971)$ & $(0.0403,0.1242,0.3828,0.7391)$ \\
PUB & $(0.1328,0.2464,0.5077,0.9535)$ & $(0.0384,0.1089,0.3461,0.7429)$ & $(0.1344,0.2102,0.4631,0.8629)$ \\
SOA & $(0.1266,0.2234,0.4858,0.9194)$ & $(0.1186,0.2397,0.4771,0.8699)$ & $(0.0327,0.0993,0.311,0.6783)$ \\
\hline
\end{tabular}


TABLE 5: The prominence matrix.

\begin{tabular}{lccc}
\hline & $C$ & $R$ & $P$ \\
\hline FAC & $(0.3642,0.845,2.3306,4.6517)$ & $(0.9158,1.8046,3.4583,6.3126)$ & $(1.28,2.6496,5.7889,10.9643)$ \\
BEH & $(0.4398,1.0402,2.5409,5.0289)$ & $(0.4784,1.0032,2.5075,5.1312)$ & $(0.9182,2.0434,5.0484,10.1601)$ \\
LR & $(0.4666,0.9758,2.5039,4.9501)$ & $(0.4698,1.0497,2.6754,5.2136)$ & $(0.9364,2.0255,5.1793,10.1637)$ \\
SC & $(0.6704,1.2944,3.008,5.8932)$ & $(0.4597,1.0507,2.6385,5.3091)$ & $(1.1301,2.3451,5.6465,11.2023)$ \\
KM & $(0.7634,1.5214,3.3006,6.289)$ & $(0.3903,0.9769,2.6507,5.1402)$ & $(1.1537,2.4983,5.9513,11.4292)$ \\
PUB & $(0.6013,1.3188,3.0615,5.8126)$ & $(0.6516,1.1846,2.9009,5.6551)$ & $(1.2529,2.5034,5.9624,11.4677)$ \\
SOA & $(0.5743,1.2028,2.8491,5.5347)$ & $(0.5144,1.1287,2.7633,5.3984)$ & $(1.0887,2.3315,5.6124,10.9331)$ \\
\hline
\end{tabular}

\section{Fuzzy Similarity Method}

The similarity method is extended for multicriteria decisionmaking in fuzzy environment. Fuzzy similarity method is proposed below in an algorithmic form.

Step 1. Let $\widetilde{X}^{l}=\left[\widetilde{x}_{i j}\right]_{n \times m}$ be a fuzzy decision matrix for the MCDM problem and the following notations are used to depict the considered problems:

$A=\left\{A_{1}, A_{2}, \ldots, A_{n}\right\}$ is the set of the considered alternatives;

$C=\left\{C_{1}, C_{2}, \ldots, C_{m}\right\}$ is the set of the criteria used for evaluating the alternatives.

Performance of alternative $A_{i}$ with respect to criterion $C_{j}$ is denoted by $\widetilde{x}_{i j}$.

Step 2 (determining the fuzzy weighting matrix). The fuzzy weight vector $\widetilde{W}$ represents the relative importance of each criterion:

$$
\widetilde{W}=\left(\widetilde{w}_{1}, \widetilde{w}_{2}, \ldots, \widetilde{w}_{j}, \ldots, \widetilde{w}_{m}\right),
$$

where $\widetilde{w}_{j}=\left(a_{j}, b_{j}, c_{j}, d_{j}\right)$ which represent the relative importance of criterion $C_{j}$ with respect to the overall objective of the problem is represented as $\widetilde{w}_{j}$.

Step 3 (normalizing the fuzzy decision matrix through linear normalization). A normalized decision matrix $\widetilde{X}^{\prime}$ can be determined as

$$
\widetilde{X}^{\prime}=\left[\widetilde{x}_{i j}^{\prime}\right]_{n \times m},
$$

where

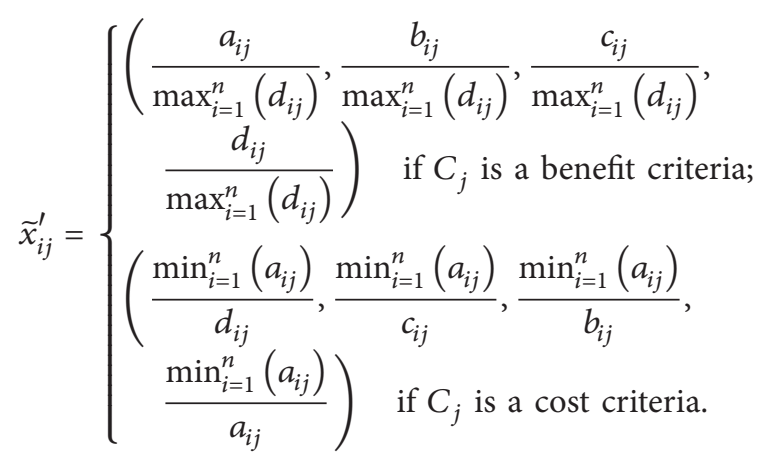

Step 4 (calculating the fuzzy performance matrix). The fuzzy performance matrix $\widetilde{Y}=\left[\tilde{y}_{i j}\right]_{n \times m}$ is calculated as follows:

$$
\tilde{y}_{i j}=\tilde{x}_{i j}^{\prime} \times \widetilde{w}_{j} \text {. }
$$

Step 5. Determine the fuzzy positive ideal solution (FPIS) and the fuzzy negative ideal solution (FNIS):

$$
\begin{aligned}
I_{j}^{+} & =\left(\max _{i=1}^{n} y_{i j}^{a}, \max _{i=1}^{n} y_{i j}^{b}, \max _{i=1}^{n} y_{i j}^{c}, \max _{i=1}^{n} y_{i j}^{d}\right), \\
I_{j}^{-} & =\left(\min _{i=1}^{n} y_{i j}^{a}, \min _{i=1}^{n} y_{i j}^{b}, \min _{i=1}^{n} y_{i j}^{c}, \min _{i=1}^{n} y_{i j}^{d}\right) .
\end{aligned}
$$

Step 6. Calculate the conflict index between the alternative and the FPIS and FNIS:

$$
\mathrm{CI}_{i}^{+}=\frac{1}{m} \sum_{j=1}^{m}\left(\tilde{y}_{i j} \times I_{j}^{+}\right), \quad \mathrm{CI}_{i}^{-}=\frac{1}{m} \sum_{j=1}^{m}\left(\tilde{y}_{i j} \times I_{j}^{-}\right),
$$

where $\mathrm{CI}_{i}^{+}=\left(\mathrm{CI}_{i}^{+^{a}}, \mathrm{CI}_{i}^{+^{b}}, \mathrm{CI}_{i}^{+^{c}}, \mathrm{CI}_{i}^{+^{d}}\right)$ and $\mathrm{CI}_{i}^{-}=\left(\mathrm{CI}_{i}^{-a}, \mathrm{CI}_{i}^{-b}\right.$, $\left.\mathrm{CI}_{i}^{-c}, \mathrm{CI}_{i}^{-d}\right)$.

Here $\mathrm{CI}_{i}^{+}$is showing the conflict index of FPIS for the overall performance matrix values. Similarly $\mathrm{CI}_{i}^{+}$is showing the conflict index of FNIS for the overall performance matrix values.

Step 7. Calculate the overall performance of alternatives by using $\mathrm{CI}_{i}^{+}$and $\mathrm{CI}_{i}^{-}$:

$$
\begin{aligned}
P_{i}= & \left(\left(\mathrm{CI}_{i}^{+^{a}} \times \mathrm{CI}_{i}^{-a}\right)+\left(\mathrm{CI}_{i}^{+^{b}} \times \mathrm{CI}_{i}^{-b}\right)\right. \\
& \left.+\left(\mathrm{CI}_{i}^{+^{c}} \times \mathrm{CI}_{i}^{-^{c}}\right)+\left(\mathrm{CI}_{i}^{+^{d}} \times \mathrm{CI}_{i}^{-d^{d}}\right)\right)(4)^{-1} .
\end{aligned}
$$

Step 8 (rank the alternatives). Rank the $P_{i}$ in descending order. The greater the value of $P_{i}$ is, the better the alternative $A_{i}$ is.

\section{Illustrative Example}

In this section, an illustrative example is given to elaborate the method proposed in Section 4, to obtain the desirable alternative. Three schools (School 1 (S1), School 2 (S2), and School 3 (S3)) all in the field of engineering are under evaluation by the Hope Education Foundation (HEF). HEF is a not for profit organization which wants to manage 
TABLE 6: (a) Average fuzzy judgment values of each $\mathrm{HC}$ indicator by expert 1. (b) Average fuzzy judgment values of each HC indicator by expert 2. (c) Average fuzzy judgment values of each $\mathrm{HC}$ indicator by expert 3 .

(a)

\begin{tabular}{|c|c|c|}
\hline \multicolumn{2}{|c|}{ Components Indicators } & S1 \\
\hline \multirow{7}{*}{ FAC } & Education & $(0.35,0.5,0.75,0.85)$ \\
\hline & Teaching experience & $(0.3,0.5,0.7,0.8)$ \\
\hline & Teaching skills & $(0.25,0.4,0.65,0.75)$ \\
\hline & Team work skills & $(0.2,0.4,0.6,0.7)$ \\
\hline & Confidence level & $(0.15,0.25,0.55,0.65)$ \\
\hline & Problem-solving skills & $(0.3,0.45,0.7,0.8)$ \\
\hline & Communication skills & $(0.4,0.55,0.8,0.9)$ \\
\hline \multirow{10}{*}{$\mathrm{BEH}$} & Personal initiative & $(0.25,0.35,0.65,0.7)$ \\
\hline & Continuous learning & $(0.45,0.55,0.75,0.85)$ \\
\hline & Conscientiousness & $(0.4,0.55,0.8,0.85)$ \\
\hline & Emotional stability & $(0.5,0.65,0.85,0.95)$ \\
\hline & Commitment & $(0.5,0.65,0.85,0.95)$ \\
\hline & Working with schools & $(0.5,0.65,0.85,0.95)$ \\
\hline & Being ethical & $(0.5,0.65,0.85,0.95)$ \\
\hline & Performing their best & $(0.5,0.65,0.8,0.95)$ \\
\hline & Eagerness to source sharing & $(0.3,0.45,0.7,0.8)$ \\
\hline & Employee satisfaction & $(0.4,0.55,0.8,0.9)$ \\
\hline \multirow[b]{2}{*}{ LR } & Availability of new books & $(0.3,0.45,0.75,0.8)$ \\
\hline & $\begin{array}{l}\text { Online resources of } \\
\text { searching }\end{array}$ & $(0.35,0.5,0.75,0.83)$ \\
\hline \multirow[t]{2}{*}{ SC } & $\begin{array}{l}\text { Freely expressing the } \\
\text { opinions }\end{array}$ & $(0.4,0.5,0.75,0.9)$ \\
\hline & Supporting new ideas & $(0.35,0.45,0.75,0.9)$ \\
\hline \multirow{3}{*}{ KM } & Creating results & $(0.45,0.65,0.85,0.95)$ \\
\hline & $\begin{array}{l}\text { Sharing and reporting } \\
\text { knowledge }\end{array}$ & $(0.4,0.55,0.8,0.9)$ \\
\hline & Information available & $(0.5,0.6,0.8,0.9)$ \\
\hline \multirow{2}{*}{ PUB } & Local publications & $(0.6,0.7,0.85,0.95)$ \\
\hline & International publications & $(0.65,0.75,0.9,1)$ \\
\hline \multirow{8}{*}{ SOA } & Students presentation & $(0.25,0.4,0.65,0.75)$ \\
\hline & Faculty talks & $(0.2,0.3,0.55,0.65)$ \\
\hline & Training programs & $(0.5,0.6,0.8,0.9)$ \\
\hline & $\begin{array}{l}\text { Succession training } \\
\text { programs }\end{array}$ & $(0.3,0.45,0.75,0.8)$ \\
\hline & Career development & $(0.4,0.55,0.8,0.9)$ \\
\hline & Job fair & $(0.2,0.35,0.65,0.7)$ \\
\hline & Invited speakers seminar & $(0.4,0.55,0.8,0.9)$ \\
\hline & Industry interest talks & $(0.45,0.6,0.85,0.95)$ \\
\hline
\end{tabular}

(b)

\begin{tabular}{llc}
\hline Components Indicators & S2 \\
\hline \multirow{4}{*}{ FAC } & Education & $(0.3,0.45,0.75,0.8)$ \\
& Teaching experience & $(0.35,0.45,0.7,0.85)$ \\
& Teaching skills & $(0.25,0.45,0.65,0.75)$ \\
& Team work skills & $(0.25,0.45,0.65,0.75)$ \\
& Confidence level & $(0.15,0.35,0.55,0.65)$ \\
& Problem-solving skills & $(0.35,0.55,0.75,0.85)$ \\
& Communication skills & $(0.4,0.6,0.8,0.9)$ \\
\hline
\end{tabular}

(b) Continued.

\begin{tabular}{|c|c|c|}
\hline Components & Indicators & S2 \\
\hline \multirow{10}{*}{$\mathrm{BEH}$} & Personal initiative & $(0.3,0.45,0.75,0.8)$ \\
\hline & Continuous learning & $(0.35,0.55,0.8,0.9)$ \\
\hline & Conscientiousness & $(0.35,0.55,0.8,0.9)$ \\
\hline & Emotional stability & $(0.45,0.55,0.85,0.95)$ \\
\hline & Commitment & $(0.48,0.55,0.85,0.95)$ \\
\hline & Working with schools & $(0.43,0.55,0.85,0.93)$ \\
\hline & Being ethical & $(0.45,0.55,0.8,0.95)$ \\
\hline & Performing their best & $(0.4,0.6,0.75,0.85)$ \\
\hline & Eagerness to source sharing & $(0.23,0.35,0.75,0.73)$ \\
\hline & Employee satisfaction & $(0.3,0.45,0.65,0.75)$ \\
\hline \multirow[b]{2}{*}{ LR } & Availability of new books & $(0.35,0.55,0.75,0.84)$ \\
\hline & $\begin{array}{l}\text { Online resources of } \\
\text { searching }\end{array}$ & $(0.35,0.55,0.8,0.88)$ \\
\hline \multirow[t]{2}{*}{ SC } & $\begin{array}{l}\text { Freely expressing the } \\
\text { opinions }\end{array}$ & $(0.35,0.45,0.75,0.85)$ \\
\hline & Supporting new ideas & $(0.35,0.45,0.75,0.85)$ \\
\hline \multirow{3}{*}{ KM } & Creating results & $(0.4,0.55,0.8,0.9)$ \\
\hline & $\begin{array}{l}\text { Sharing and reporting } \\
\text { knowledge }\end{array}$ & $(0.4,0.55,0.8,0.85)$ \\
\hline & Information available & $(0.4,0.55,0.8,0.9)$ \\
\hline \multirow{2}{*}{ PUB } & Local publications & $(0.45,0.55,0.75,0.85)$ \\
\hline & International publications & $(0.55,0.65,0.85,0.95)$ \\
\hline \multirow{8}{*}{ SOA } & Students presentation & $(0.25,0.45,0.65,0.75)$ \\
\hline & Faculty talks & $(0.25,0.45,0.65,0.75)$ \\
\hline & Training programs & $(0.45,0.65,0.8,0.9)$ \\
\hline & $\begin{array}{l}\text { Succession training } \\
\text { programs }\end{array}$ & $(0.25,0.45,0.65,0.75)$ \\
\hline & Career development & $(0.3,0.45,0.75,0.8)$ \\
\hline & Job fair & $(0.2,0.35,0.6,0.7)$ \\
\hline & Invited speakers seminar & $(0.35,0.55,0.75,0.85)$ \\
\hline & Industry interest talks & $(0.35,0.5,0.7,0.8)$ \\
\hline \multicolumn{3}{|c|}{ (c) } \\
\hline Components & Indicators & S3 \\
\hline \multirow{7}{*}{ FAC } & Education & $(0.4,0.55,0.8,0.9)$ \\
\hline & Teaching experience & $(0.35,0.6,0.8,0.9)$ \\
\hline & Teaching skills & $(0.3,0.45,0.75,0.85)$ \\
\hline & Team work skills & $(0.2,0.35,0.65,0.7)$ \\
\hline & Confidence level & $(0.2,0.4,0.65,0.7)$ \\
\hline & Problem-solving skills & $(0.35,0.55,0.75,0.85)$ \\
\hline & Communication skills & $(0.35,0.55,0.75,0.85)$ \\
\hline \multirow{10}{*}{$\mathrm{BEH}$} & Personal initiative & $(0.35,0.45,0.75,0.85)$ \\
\hline & Continuous learning & $(0.5,0.65,0.85,0.95)$ \\
\hline & Conscientiousness & $(0.4,0.6,0.8,0.85)$ \\
\hline & Emotional stability & $(0.45,0.65,0.85,0.95)$ \\
\hline & Commitment & $(0.45,0.65,0.85,0.95)$ \\
\hline & Working with schools & $(0.4,0.65,0.85,0.9)$ \\
\hline & Being ethical & $(0.4,0.55,0.8,0.9)$ \\
\hline & Performing their best & $(0.4,0.55,0.8,0.85)$ \\
\hline & $\begin{array}{l}\text { Eagerness to source } \\
\text { sharing }\end{array}$ & $(0.43,0.6,0.8,0.9)$ \\
\hline & Employee satisfaction & $(0.3,0.55,0.8,0.85)$ \\
\hline
\end{tabular}


(c) Continued.

\begin{tabular}{llc}
\hline Components & Indicators & S3 \\
\hline \multirow{2}{*}{ LR } & $\begin{array}{l}\text { Availability of new books } \\
\text { Online resources of }\end{array}$ & $(0.45,0.55,0.85,0.95)$ \\
& searching & $(0.4,0.55,0.85,0.95)$ \\
\hline \multirow{3}{*}{ SC } & Freely expressing the & $(0.45,0.55,0.8,0.95)$ \\
& opinions & $(0.4,0.55,0.8,0.9)$ \\
\hline \multirow{4}{*}{ KM } & Supporting new ideas & $(0.45,0.65,0.85,0.95)$ \\
& Creating results & $(0.45,0.65,0.85,0.9)$ \\
& Sharing and reporting & $(0.5,0.7,0.9,1)$ \\
\hline \multirow{2}{*}{ kUB } & Informatedge & $(0.5,0.65,0.8,0.9)$ \\
& Local publications & $(0.45,0.6,0.85,0.95)$ \\
\hline \multirow{4}{*}{ International publications } & $(0.3,0.45,0.75,0.8)$ \\
& Students presentation & $(0.2,0.35,0.6,0.7)$ \\
& Faculty talks & $(0.55,0.7,0.8,0.95)$ \\
& Training programs & $(0.35,0.45,0.75,0.8)$ \\
& Succession training & $(0.3,0.45,0.7,0.8)$ \\
& programs & $(0.3,0.45,0.65,0.75)$ \\
& Career development & $(0.35,0.55,0.75,0.85)$ \\
& Job fair & $(0.55,0.7,0.85,0.95)$ \\
\hline & Invited speakers seminar &
\end{tabular}

the allocation of funds to these engineering schools based on their performance.

There are seven components and their thirty-four indicators of capacity were taken as the framework for assessing the capability of schools. Firstly, the fuzzy DEMATEL method was used to obtain the fuzzy weights of the components. We use the fuzzy similarity method to rank the schools by using the weights of components.

We use fuzzy DEMATEL method to evaluate the relative weights of components. These seven components are faculty (FAC), behavior (BEH), library resources (LR), study culture (SC), knowledge management (KM), publications (PUB), and seminar organized activities (SOA). A committee of ten experts as representatives was formed to evaluate the influential relation of these seven components on each other. Experts filled the judgment matrix through linguistic terms. These linguistic terms transfer to the corresponding trapezoidal fuzzy numbers. The pairwise comparison of experts about the influence of components on each other is being used as the inputs of the paired comparison matrix in the fuzzy DEMATEL method (see Table 1).

First there are the following steps of fuzzy DEMATEL method for calculating the relative weights of component.

Step 1. Take average of ten experts pairwise comparison matrix. The fuzzy direct relation matrix is calculated in Table 2.

Step 2. The normalized direct relation matrix is calculated and given in Table 3.

Step 3. The fuzzy total relation matrix is calculated and shown in Table 4.
Step 4. The importance of each component is computed in prominence matrix and shown in Table 5.

Next, there are the following steps of fuzzy similarity method for ranking of schools.

Step 1 (determining the fuzzy decision matrix). Three experts categorize the thirty-four $\mathrm{HC}$ indicators under seven components in Tables 6(a), 6(b), and 6(c). The overall fuzzy decision matrix for the seven components and three alternatives is given in Table 7.

Step 2 (determining the fuzzy weighting matrix). The fuzzy prominence matrix $P$ is obtained from fuzzy DEMATEL method and normalized it. After this, it is applied as the weights of components in this step. The fuzzy weighting matrix is shown in Table 8.

Step 3 (normalizing the fuzzy decision matrix through linear normalization). The normalized fuzzy decision matrix is as shown in Table 9.

Step 4 (calculating the fuzzy performance matrix). The fuzzy performance matrix is calculated and is displayed in Table 10 .

Step 5. The fuzzy PIS and the fuzzy NIS for each criterion are calculated and shown in Table 11.

Step 6. Calculate the conflict index between the alternatives and the PIS and the NIS, shown in Table 12.

Step 7. Calculate the overall performance of each alternative, shown in Table 13.

Step 8 (rank the alternatives). In this example, we use the defuzzification to rank the alternatives which is shown in Table 14.

Rank all the alternatives $S i(i=1,2,3)$ according to $P$ :

$$
\mathrm{S} 3>\mathrm{S} 1>\mathrm{S} 2 .
$$

Thus, the most desirable alternative is S3.

\section{Discussion and Conclusion}

Fuzzy similarity MCDM method is introduced to rank the performance evaluation. Capability should also put more emphasis on the most important components. A comparative study on ranking of three schools using a fuzzy MCDM approach based on the components and their related indicators is presented. Framework for capability measurement is based on thirty-four indicators and summarized in seven components. Fuzzy DEMATEL method was employed to evaluate the influential relations of the components and their relative importance. It has the greatest fuzzy weight according to experts' opinions. The prioritization of components can help managers to make good use of the limited resources to improve those aspects that are important. Our proposed fuzzy MCDM framework has important points to improve the process of assessing schools' capabilities. 
TABle 7: The fuzzy decision matrix.

\begin{tabular}{lccc}
\hline Components & S1 & S2 & S3 \\
\hline FAC & $(0.278571,0.4357,0.67857,0.77857)$ & $(0.2928,0.4714,0.7167,0.7928)$ & $(0.307,0.4928,0.7357,0.8214)$ \\
BEH & $(0.43,0.57,0.79,0.885)$ & $(0.374,0.515,0.785,0.871)$ & $(0.408,0.59,0.815,0.895)$ \\
LR & $(0.325,0.475,0.75,0.815)$ & $(0.35,0.55,0.775,0.86)$ & $(0.425,0.55,0.85,0.95)$ \\
SC & $(0.375,0.475,0.75,0.9)$ & $(0.35,0.45,0.75,0.85)$ & $(0.425,0.55,0.8,0.925)$ \\
KM & $(0.45,0.6,0.8167,0.9167)$ & $(0.4,0.55,0.8,0.883)$ & $(0.467,0.667,0.867,0.95)$ \\
PUB & $(0.625,0.725,0.875,0.975)$ & $(0.5,0.6,0.8,0.9)$ & $(0.475,0.625,0.825,0.925)$ \\
SOA & $(0.3375,0.475,0.73125,0.81875)$ & $(0.3,0.48125,0.69375,0.7875)$ & $(0.3625,0.5125,0.73125,0.825)$ \\
\hline
\end{tabular}

TABLE 8: The fuzzy weighting matrix.

\begin{tabular}{ll}
\hline Components & Fuzzy weights \\
\hline FAC & $(0.111614928,0.231042902,0.504787234,0.956077782)$ \\
BEH & $(0.080066271,0.178182769,0.440216254,0.885952215)$ \\
LR & $(0.081653296,0.176621904,0.451630624,0.886266132)$ \\
SC & $(0.098543774,0.204490757,0.492370073,0.976831182)$ \\
KM & $(0.100601674,0.217849669,0.518948378,0.996616672)$ \\
PUB & $(0.109251831,0.218294384,0.519916289,0.99997384)$ \\
SOA & $(0.094933729,0.203304848,0.489396582,0.953357168)$ \\
\hline
\end{tabular}

TABLE 9: The normalized fuzzy decision matrix.

\begin{tabular}{|c|c|}
\hline Components & S1 \\
\hline FAC & $(0.339130435,0.530434783,0.826086957,0.947826087)$ \\
\hline $\mathrm{BEH}$ & $(0.480446927,0.636871508,0.882681564,0.988826816)$ \\
\hline LR & $(0.342105263,0.5,0.789473684,0.857894737)$ \\
\hline SC & $(0.405405405,0.513513514,0.810810811,0.972972973)$ \\
\hline KM & $(0.473684211,0.631578947,0.859649123,0.964912281)$ \\
\hline PUB & $(0.641025641,0.743589744,0.897435897,1)$ \\
\hline SOA & $(0.409090909,0.575757576,0.886363636,0.992424242)$ \\
\hline Components & S2 \\
\hline FAC & $(0.356521739,0.573913044,0.872463769,0.965217392)$ \\
\hline $\mathrm{BEH}$ & $(0.417877095,0.575418994,0.877094972,0.973184358)$ \\
\hline LR & $(0.368421053,0.578947368,0.815789474,0.905263158)$ \\
\hline SC & $(0.378378378,0.486486486,0.810810811,0.918918919)$ \\
\hline KM & $(0.421052632,0.578947368,0.842105263,0.929824561)$ \\
\hline PUB & $(0.512820513,0.615384615,0.820512821,0.923076923)$ \\
\hline SOA & $(0.363636364,0.583333333,0.840909091,0.954545455)$ \\
\hline Components & S3 \\
\hline FAC & $(0.373913044,0.6,0.895652174,1)$ \\
\hline $\mathrm{BEH}$ & $(0.455865922,0.659217877,0.910614525,1)$ \\
\hline LR & $(0.447368421,0.578947368,0.894736842,1)$ \\
\hline SC & $(0.459459459,0.594594595,0.864864865,1)$ \\
\hline KM & $(0.49122807,0.701754386,0.912280702,1)$ \\
\hline PUB & $(0.487179487,0.641025641,0.846153846,0.948717949)$ \\
\hline SOA & $(0.439393939,0.621212121,0.886363636,1)$ \\
\hline
\end{tabular}


TABLE 10: The fuzzy performance matrix.

\begin{tabular}{|c|c|}
\hline Components & S1 \\
\hline FAC & $\begin{array}{l}(0.037852019,0.122553192,0.41699815 \\
0.906195463)\end{array}$ \\
\hline $\mathrm{BEH}$ & $\begin{array}{l}(0.038467594,0.113479529,0.388570772, \\
0.876053307)\end{array}$ \\
\hline LR & $\begin{array}{l}(0.027934022,0.088310952,0.356550493, \\
0.76032305)\end{array}$ \\
\hline SC & $\begin{array}{l}(0.039950179,0.105008767,0.399218978 \\
0.95043034)\end{array}$ \\
\hline $\mathrm{KM}$ & $\begin{array}{l}(0.047653425,0.137589264,0.446113518 \\
0.961647666)\end{array}$ \\
\hline PUB & $\begin{array}{l}(0.070033225,0.162321465,0.466591541 \\
0.99997384)\end{array}$ \\
\hline SOA & $\begin{array}{l}(0.038836525,0.117054307,0.433783334 \\
0.946134765)\end{array}$ \\
\hline Components & $\mathrm{S} 2$ \\
\hline FAC & $\begin{array}{l}(0.039793148,0.132598535,0.440408573, \\
0.922822903)\end{array}$ \\
\hline $\mathrm{BEH}$ & $\begin{array}{l}(0.033457861,0.10252975,0.386111463 \\
0.862194837)\end{array}$ \\
\hline LR & $\begin{array}{l}(0.030082793,0.102254787,0.368435509 \\
0.802304077)\end{array}$ \\
\hline SC & $\begin{array}{l}(0.037286833,0.09948199,0.399218978 \\
0.897628654)\end{array}$ \\
\hline $\mathrm{KM}$ & $\begin{array}{l}(0.0423586,0.126123492,0.437009161, \\
0.92667866)\end{array}$ \\
\hline PUB & $\begin{array}{l}(0.05602658,0.134335006,0.426597981 \\
0.923052776)\end{array}$ \\
\hline SOA & $\begin{array}{l}(0.034521356,0.118594495,0.411538035 \\
0.910022751)\end{array}$ \\
\hline Components & S3 \\
\hline FAC & $\begin{array}{l}(0.041734278,0.138625741,0.452113784 \\
0.956077782)\end{array}$ \\
\hline $\mathrm{BEH}$ & $\begin{array}{l}(0.036499485,0.117461267,0.400867315 \\
0.885952215)\end{array}$ \\
\hline LR & $\begin{array}{l}(0.036529106,0.102254787,0.404090559 \\
0.886266132)\end{array}$ \\
\hline SC & $\begin{array}{l}(0.045276869,0.121589099,0.425833577 \\
0.976831182)\end{array}$ \\
\hline $\mathrm{KM}$ & $\begin{array}{l}(0.049418366,0.15287696,0.473426591 \\
0.996616672)\end{array}$ \\
\hline PUB & $\begin{array}{l}(0.053225251,0.139932298,0.439929167 \\
0.94869313)\end{array}$ \\
\hline SOA & $\begin{array}{l}(0.041713305,0.126295436,0.433783334 \\
0.953357168)\end{array}$ \\
\hline
\end{tabular}

Fuzzy DEMATEL method is used to consider the possible interrelationships among components.

\section{Conflict of Interests}

The authors declare that there is no conflict of interests.
TABLE 11: The fuzzy PIS and the fuzzy NIS.

\begin{tabular}{ll}
\hline Components & PIS \\
\hline FAC & $(0.041734278,0.138625741,0.452113784,0.956077782)$ \\
BEH & $(0.038467594,0.117461267,0.400867315,0.885952215)$ \\
LR & $(0.036529106,0.102254787,0.404090559,0.886266132)$ \\
SC & $(0.045276869,0.121589099,0.425833577,0.976831182)$ \\
KM & $(0.049418366,0.15287696,0.473426591,0.996616672)$ \\
PUB & $(0.070033225,0.162321465,0.466591541,0.99997384)$ \\
SOA & $(0.041713305,0.126295436,0.433783334,0.953357168)$ \\
\hline Components & NIS \\
\hline FAC & $(0.037852019,0.122553192,0.41699815,0.906195463)$ \\
BEH & $(0.033457861,0.10252975,0.386111463,0.862194837)$ \\
LR & $(0.027934022,0.088310952,0.356550493,0.76032305)$ \\
SC & $(0.037286833,0.09948199,0.399218978,0.897628654)$ \\
KM & $(0.0423586,0.126123492,0.437009161,0.92667866)$ \\
PUB & $(0.053225251,0.134335006,0.426597981,0.923052776)$ \\
SOA & $(0.034521356,0.117054307,0.411538035,0.910022751)$ \\
\hline
\end{tabular}

TABLE 12: Conflict index between the alternatives and the PIS and the NIS.

\begin{tabular}{lc}
\hline & $\mathrm{CI}^{+}$ \\
\hline S1 & $(0.002109759,0.016326075,0.182207588,0.872162774)$ \\
S2 & $(0.001884561,0.015577369,0.179604788,0.849741319)$ \\
S3 & $(0.00206284,0.017184302,0.189613263,0.898495123)$ \\
\hline & $\mathrm{CI}^{-}$ \\
\hline S1 & $(0.001725215,0.013965717,0.168992025,0.811844952)$ \\
S2 & $(0.001546332,0.013360662,0.166542811,0.79061236)$ \\
S3 & $(0.00169654,0.014717293,0.1757818,0.835392992)$ \\
\hline
\end{tabular}

TABLE 13: Overall performance of each alternative.

\begin{tabular}{ll}
\hline & $\mathrm{CI}^{+} \times \mathrm{CI}^{-}$ \\
\hline S1 & $(0.000003639,0.000228,0.030791,0.70806)$ \\
S2 & $(0.000002914,0.000208,0.02991,0.6718)$ \\
S3 & $(0.000003499,0.0002529,0.03333,0.75059)$ \\
\hline
\end{tabular}

TABLE 14: Ranking of alternatives.

\begin{tabular}{lcc}
\hline & $P$ & Ranking \\
\hline S1 & 0.184771055 & 2 \\
S2 & 0.175484729 & 3 \\
S3 & 0.196045874 & 1 \\
\hline
\end{tabular}

\section{Acknowledgment}

The authors thank the referees for the thoughtful comments. They owe much of the present version of the paper to the precise and kind remarks of the referees.

\section{References}

[1] T. Özcan, N. Elebi, and A. Esnaf, "Comparative analysis of multi-criteria decision making methodologies and implementation of a warehouse location selection problem," Expert Systems with Applications, vol. 38, no. 8, pp. 9773-9779, 2011. 
[2] L. A. Zadeh, "Fuzzy sets," Information and Control, vol. 8, pp. 338-356, 1965.

[3] L. A. Zadeh, "The concept of a linguistic variable and its application to approximate reasoning-I," Information Sciences, vol. 8, no. 3, pp. 199-249, 1975.

[4] C.-T. Lin and Y.-T. Chen, "Bid/no-bid decision-making-a fuzzy linguistic approach," International Journal of Project Management, vol. 22, no. 7, pp. 585-593, 2004.

[5] R.-C. Wang and S.-J. Chuu, "Group decision-making using a fuzzy linguistic approach for evaluating the flexibility in a manufacturing system," European Journal of Operational Research, vol. 154, no. 3, pp. 563-572, 2004.

[6] D. Dubois, "The role of fuzzy sets in decision sciences: old techniques and new directions," Fuzzy Sets and Systems, vol. 184, pp. 3-28, 2011.

[7] I. Beg and T. Rashid, “TOPSIS for hesitant fuzzy linguistic term sets," International Journal of Intelligent Systems, vol. 28, no. 12, pp. 1162-1171, 2013.

[8] I. Beg and T. Rashid, "Multi-criteria trapezoidal valued intuitionistic fuzzy decision making with Choquet integral based TOPSIS," OPSEARCH, vol. 51, no. 1, pp. 98-129, 2014.

[9] Y.-J. Wang and H.-S. Lee, "Generalizing TOPSIS for fuzzy multiple-criteria group decision-making," Computers \& Mathematics with Applications, vol. 53, no. 11, pp. 1762-1772, 2007.

[10] C. L. Hwang and K. Yoon, Multiple Attribute Decision Making, vol. 186, Springer, Berlin, Germany, 1981.

[11] Y.-T. Lin, Y.-H. Yang, J.-S. Kang, and H.-C. Yu, "Using DEMATEL method to explore the core competences and causal effect of the IC design service company: an empirical case study," Expert Systems with Applications, vol. 38, no. 5, pp. 6262-6268, 2011.

[12] C.-W. Hsu, T.-C. Kuo, S.-H. Chen, and A. H. Hu, "Using DEMATEL to develop a carbon management model of supplier selection in green supply chain management," Journal of Cleaner Production, vol. 56, pp. 164-172, 2013.

[13] D. J.-F. Jeng and G.-H. Tzeng, "Social influence on the use of clinical decision support systems: revisiting the United Theory of acceptance and use of technology by the fuzzy DEMATEL technique," Computers and Industrial Engineering, vol. 62, no. 3, pp. 819-828, 2012.

[14] H. Deng, "A similarity-based approach to ranking multicriteria alternatives," in Advanced Intelligent Computing Theories and Applications. With Aspects of Artificial Intelligence: Proceedingsof the 3 rd International Conference on Intelligent Computing, ICIC 2007, Qingdao, China, August 21-24, 2007, vol. 4682 of Lecture Notes in Computer Science, pp. 253-262, Springer, Berlin, Germany, 2007.

[15] S. F. Schnatter, "On statistical inference for fuzzy data with applications to descriptive statistics," Fuzzy Sets and Systems, vol. 50, no. 2, pp. 143-165, 1992.

[16] H.-J. Zimmermann, Fuzzy Set Theory and Its Applications, Kluwer Academic, Dordrecht, The Netherlands, 1991.

[17] H. T. Nguyen and E. Walker, Fuzzy Logic, Chapman \& Hall; CRC Press, New York, NY, USA, 3rd edition, 2006.

[18] I. Beg and T. Rashid, "A democratic preference aggregation model," Journal of Uncertainty Analysis and Applications, vol. 1, no. 1, article 5, 2013. 


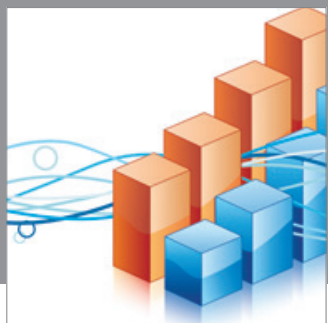

Advances in

Operations Research

mansans

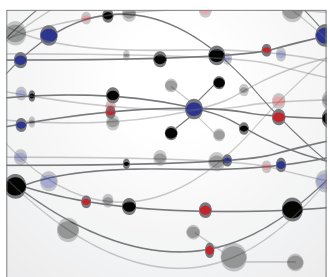

The Scientific World Journal
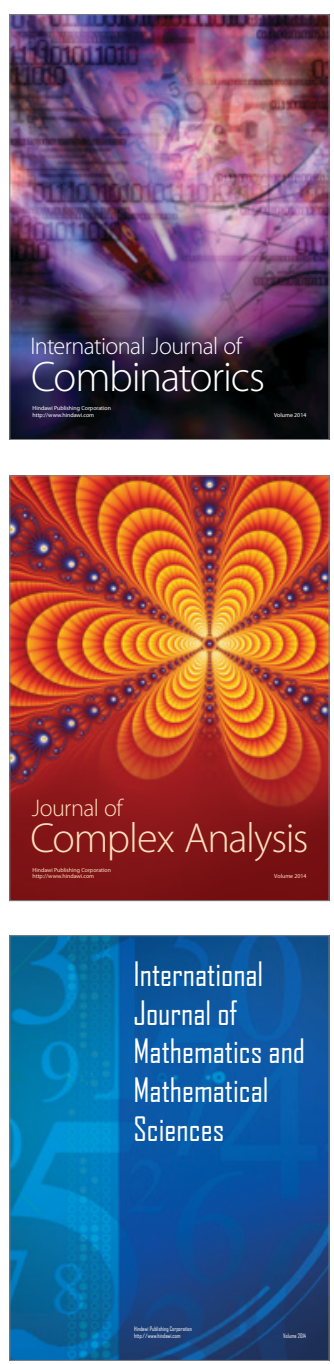
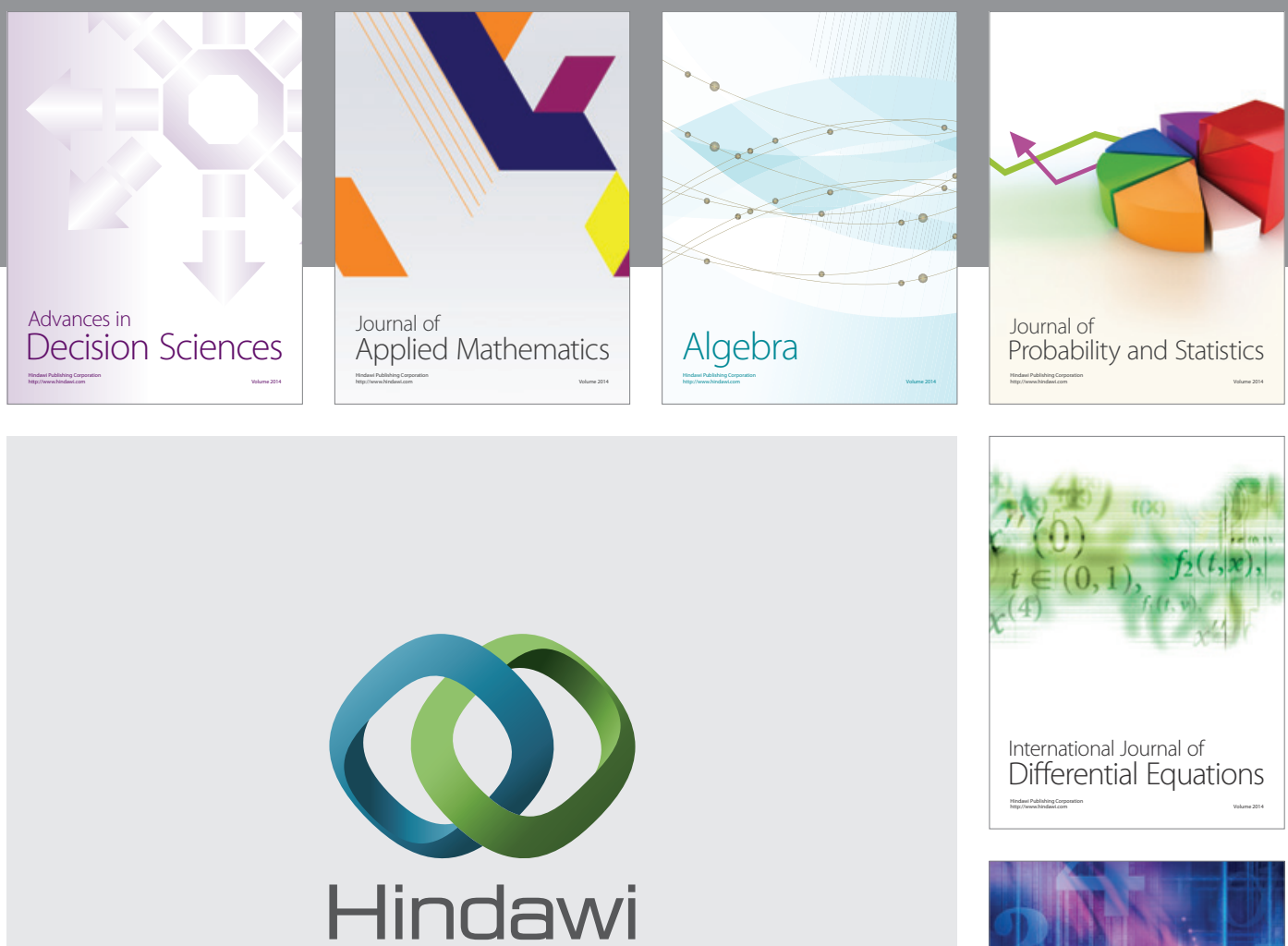

Submit your manuscripts at http://www.hindawi.com
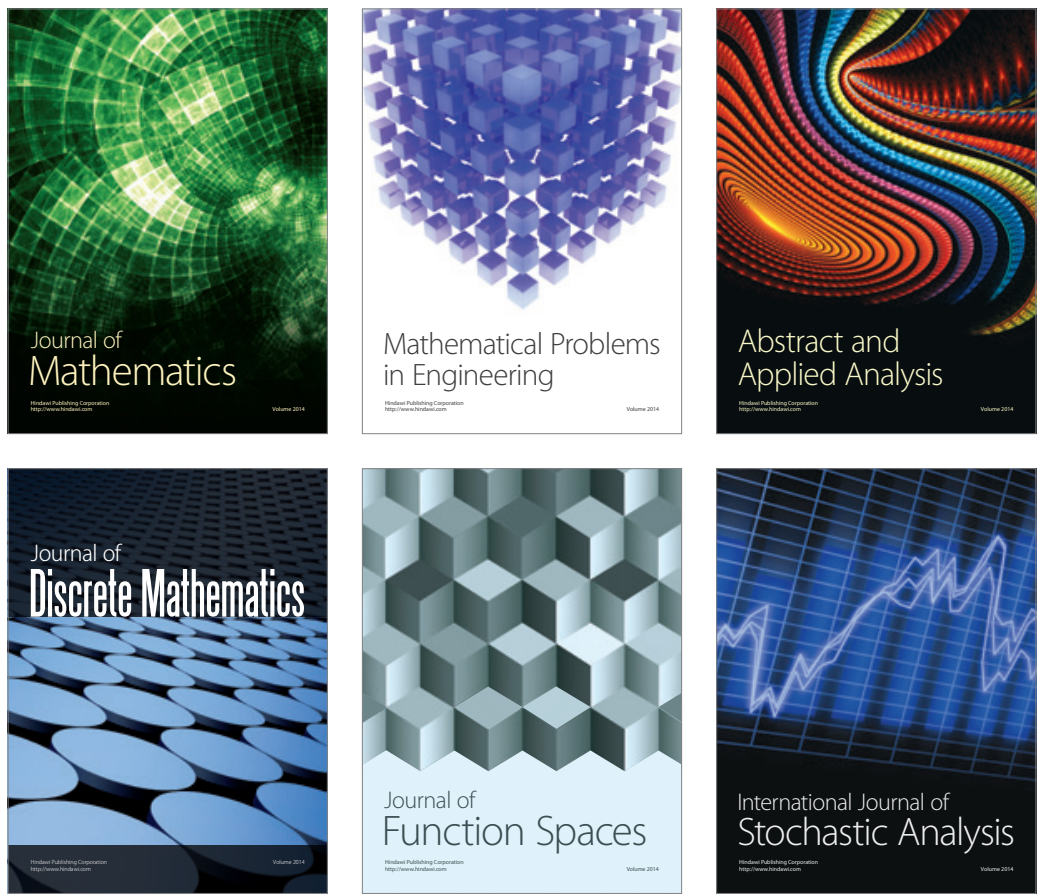

Journal of

Function Spaces

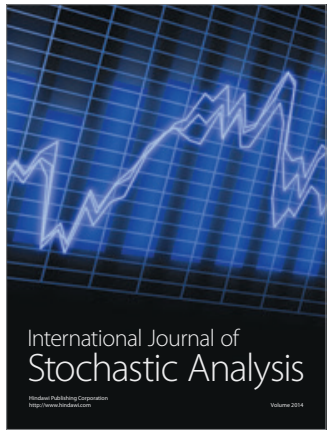

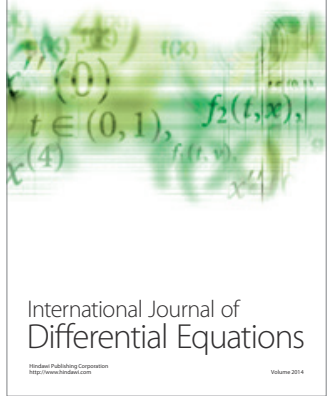
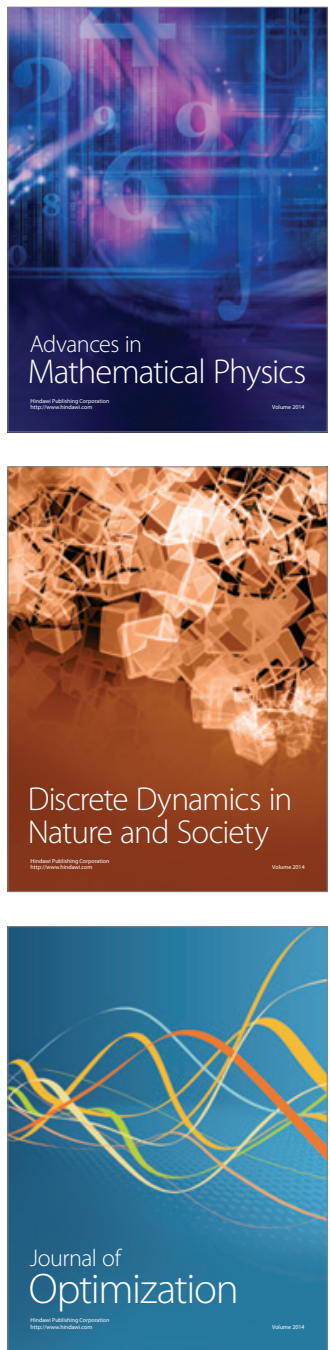